\title{
Recidivous cholesteatoma: DWI MR after canal wall up and canal wall down mastoidectomy
}

\author{
Bakaj $\mathrm{T}^{1,3}$, Bakaj Zbrozkova $\mathrm{L}^{2,3}$, Salzman $\mathrm{R}^{1,3}$, Tedla $\mathrm{M}^{4}$, Starek $\mathrm{I}^{1,3}$ \\ Department of Otorhinolaryngology, University Hospital Olomouc, Olomouc, Czech Republic. \\ bakaj.t@seznam.cz
}

\section{ABSTRACT}

OBJECTIVES: To investigate the correlation between preoperative non-echo planar diffusion-weighted (non-EPI DWI) MR imaging with surgical findings of recidivous middle ear cholesteatoma after canal wall up (CWU) and canal wall down (CWD) mastoidectomy.

BACKGROUND: The detection of recidive cholesteatoma after CWU and after CWD procedures, when the trepanation cavity is spontaneously closed by soft tissue, is possible by second-look and revision surgery. However, many cases prove to be negative of the disease. To avoid unnecessary operational risks we adopted a novel imaging method to evaluate its potential in the detection of recidivous cholesteatoma.

MATERIALAND METHODS: The prospective study included 27 cases. Fifteen cases were revised after CWD and 12 cases were second-look surgeries after CWU procedures. All patients underwent the MR protocol: T2-weighted, T1-weighted and non-EPI DWI. The finding on MR correlated with peroperative presence of cholesteatoma. RESULTS: Non-EPI DWI sequence showed an increased signal intensity in 16/27 (59 \%) cases. This correlated with surgical findings in all 7 patients after CWU and in 8 patients after CWD.

The overall sensitivity, specificity, positive and negative predictive values of non-EPI DWI were $83.3 \%, 88.8 \%$, $93.8 \%$ and $72.7 \%$, respectively. DWI presented a sensitivity of $100 \%$ and specificity of $85.7 \%$ in the subgroup of patients after CWD mastoidectomy.

CONCLUSION: Residual and/or recurrent cholesteatoma can be accurately detected by DWI MR. It can be used as a screening method to select patients, who are indicated to second-look or revision surgery after CWU and CWD mastoidectomy (Tab. 1, Fig. 3, Ref. 49). Text in PDF www.elis.sk.

KEY WORDS: canal wall down (CWD), canal wall up (CWU), recidivism, cholesteatoma, non-echo planar diffusion-weighted imaging (non-EPI DWI), MR.

\section{Introduction}

Cholesteatoma is a cystic pseudotumor located mostly in the middle ear, and less frequently in other areas of the temporal bone (1). Etiopathogenetically, it is regarded as a heterogeneous disease, where besides embryonic disorders (congenital cholesteatoma), there are other participating postnatal factors like epithelial metaplasia, retraction pocket and dysfunctional eustachian tube (acquired cholesteatoma) (2). Its wall, called matrix, consists of keratin producing squamous epithelium (3). On its outer circum-

\footnotetext{
'Department of Otorhinolaryngology, University Hospital Olomouc, Olomouc, Czech Republic, ${ }^{2}$ Department of Radiology, University Hospital Olomouc, Olomouc, Czech Republic, ${ }^{3}$ Faculty of Medicine and Dentistry, Palacky University Olomouc, Olomouc, Czech Republic, and ${ }^{4}$ Department of ORL HNS, Medical school of Comenius University and University Hospital Bratislava, Bratislava, Slovakia
}

Address for correspondence: T. Bakaj, MD, Department of Otorhinolaryngology, University Hospital Olomouc, IP Pavlova 6, CZ-779 00, Olomouc, Czech Republic.

Phone: +420.777864164, Fax: +420.588442518

Acknowledgement: This study was supported by the Institutional Support of the Ministry of Health, Czech Republic, Nr. 1RVO-FNOL2016, RVO: 61989592. ference, there is sometimes a layer of granulation tissue - perimatrix, which actively participates in invasive growth.

Cholesteatoma, by the pressure and due to collagenases, causes osteoclastic remodeling of the bone and its necrosis. This leads to erosion of osseous structures of the petrous bone and middle ear ossicles, which can be exacerbated by secondary bacterial inflammation. The incidence of all forms of cholesteatoma in adults is around $10-13 / 100000$ and 3/100 000 in children.

Primary middle ear cholesteatoma is usually diagnosed by medical history, audiometric examination, otomicroscopical examination and high-resolution computed tomography (HRCT) (4).

Currently, the only therapeutic solution of cholesteatoma is surgical excision (5). It also has a prophylactic effect on intratemporal and/or intracranial complications. The main goal is to control disease, that is, to create a dry, trouble-free, and recurrence-free ear with hearing preservation or reconstruction.

Surgically, we can perform an open technique, called canal wall down (CWD), in which the posterior auditory canal wall and lateral attic wall is removed to create a common cavity, which combines the ear canal and mastoid (6). This technique provides the surgeon a larger surgical exposure, and so is associated with a lower recurrence cholesteatoma rate, $0-13 \%$ (7). Its disadvantage, however, resulted from an open cavity, contributes to restrictions 


\section{$515-520$}

in patients' daily life: the need for consequent water protection, frequent cleaning of the mastoid cavity by an otologist, as well as usually chronically draining ear, which requires conservative treatment (8). Recidivous disease most often occur in the cavity, is then accurately detected on follow-up by otomicroscopical examination, which led to a revision surgery.

For the above mentioned disadvantages, some authors carry out reconstruction of posterior wall or obliteration of the cavity using various methods $(9,10)$.

Another option is to preserve the posterior wall of the external auditory meatus, called canal wall up (CWU) technique (11). The advantage is the absence of an open cavity and, according to some authors, it also provides better auditory gains (12). Thereat, there is an increasing tendency amongst otologists to practise intact canal mastoidectomy.

CWU, compared with CWD is associated with about a 3-fold higher risk of recurrent or residual disease (13). This is mainly due to a smaller overview of the surgical field (14). Residual disease occurs in the areas hidden from clinical inspection. Therefore, at an interval of 9-24 months, a planned, control, second-look operation is indicated. However, in about $2 / 3$ of patients, the absence of relapsing cholesteatoma exposes these patients to unnecessary operational risks.

Therefore, less invasive, imaging methods for detection of residual and/or recurrent cholesteatoma were examined.

High-resolution computed tomography has been shown to be unreliable in differentiating recidivous cholesteatoma from the other pathological lesions (15). The cardinal HRCT sign of cholesteatoma, erosion of adjacent bone and ossiculars, is not applicable in the postoperative ear because of the surgical modification of the bony and ossicular landmarks. This disadvantage is compensated with non-echo planar DWI, presented as at first by Dubrulle in 2006 (16), which has very good reliability and low inclination to artefacts, used in the differential diagnosis of soft tissue (17). It is based on the detection of the random microscopic motion of water protons in the presence of the strong magnetic field gradients (18). This proton self-diffusion is limited in cholesteatoma, as the accumulated keratin comprises a minimal amount of water, which on diffusionweighted imaging (DWI) sequences, predominantly with contribution of T2, ,shine-through“ effect, show as increased signal intensity in comparison with the brain/other surrounding soft tissues.

The aim of this study was to evaluate the diagnostic accuracy, expressed as sensitivity, specificity, positive and negative predictive value of non-echo planar diffusion-weighted MR imaging in our hospital for the detection of recidive middle ear cholesteatoma after CWU and CWD procedures.

\section{Materials and methods}

\section{Research design}

This single-centre prospective observational study was conducted at the University Hospital Olomouc. In 2012, the non-EPI DWI sequence was introduced for screening for residual and/or recurrent cholesteatoma in the postoperative patients. That year we didn't have any experience with these specific MR sequence.
The ENT surgeons decided that patients after CWU operations requiring second-look surgery and patients who underwent CWD procedures would be included in the study.

Decision for the second-look surgery was made by the surgeon on the basis of findings at the first stage surgery and on clinical follow-up $(19,20)$, for the revision surgery after CWD mastoidectomy on postoperative clinical findings or DWI MR results.

\section{Patients}

The study group consisted of 24 patients; 13 males and 11 females, with the mean age 34 (9-63) years, in the period from $12 / 2013$ to $12 / 2015$. One patient underwent a revision surgery after CWD with the reconstruction of the posterior ear canal ensued by second-look, one underwent second-look and third-look surgery and another a revision operation after CWD twice. The total number of MR examined and operated ears was 27, of which 12 cases were second-look surgeries after CWU for cholesteatoma, which according to practise in our department were performed 9-14 months after the initial operation.

15 cases were revision surgeries after CWD, performed $12-$ 248 (mean 72) months years after the primary surgery. 8/15 (53 $\%$ ) cases had a spontaneous complete closure of the trepanation cavity by soft tissue, making the otomicroscopical examination in the detection of recidive cholesteatoma impossible (Fig. 1). $7 / 15(47 \%)$ cases had discharging cavities with the presence of inflammatory/granulation tissues and no apparent cholesteatoma.

\section{Imaging technique}

Examinations were performed at 1.5T MR unit Avanto (Siemens, Erlangen Germany) using a standard head coil. Imaging protocol contains the following sequences: a turbo spin echo T2weighted images width of $5 \mathrm{~mm}$ in the axial and coronal plane (TR $4640 \mathrm{~ms}$, TE $103 \mathrm{~ms}$, field of view $235 \mathrm{~mm}$, matrix $296 \mathrm{x}$ 384 ), spin echo T1-weighted images of width $4 \mathrm{~mm}$ in the sagital plane (TR $552 \mathrm{~ms}$, TE $8.4 \mathrm{~ms}$, field of view $240 \mathrm{~mm}$, matrix 256 $\mathrm{x}$ 256), turbo spin echo sequence DWI Fourier Half-acquisition single-shot turbo spin echo (HASTE) width of $4 \mathrm{~mm}$ in the axial plane (TR $2200 \mathrm{~ms}$, TE $127 \mathrm{~ms}$, field of view $230 \mathrm{~mm}$, matrix $192 \times 192, \mathrm{~b}$ factor of $1000 \mathrm{~s} / \mathrm{mm}^{2}$ ).

\section{Imaging evaluation}

Two experienced head and neck radiologists evaluated independently all MR images without the knowledge of any surgical or clinical information about patients. As cholesteatoma were considered soft tissue lesion with a low signal intensity on T1weighted images, an increased signal intensity on T2 and a high signal intensity in comparison with brain tissue on non-EPI DWI. The size of the lesions in its maximal transversal diameter was determined on DWI sequence.

\section{Surgery}

The interval between MR examination and surgery was $0-232$, mean 33 days. Majority ( $56 \%$ ) of the patients were operated on within 3 weeks after MR. Indications for the second-look surgery after CWU were independent of the MR results, which 


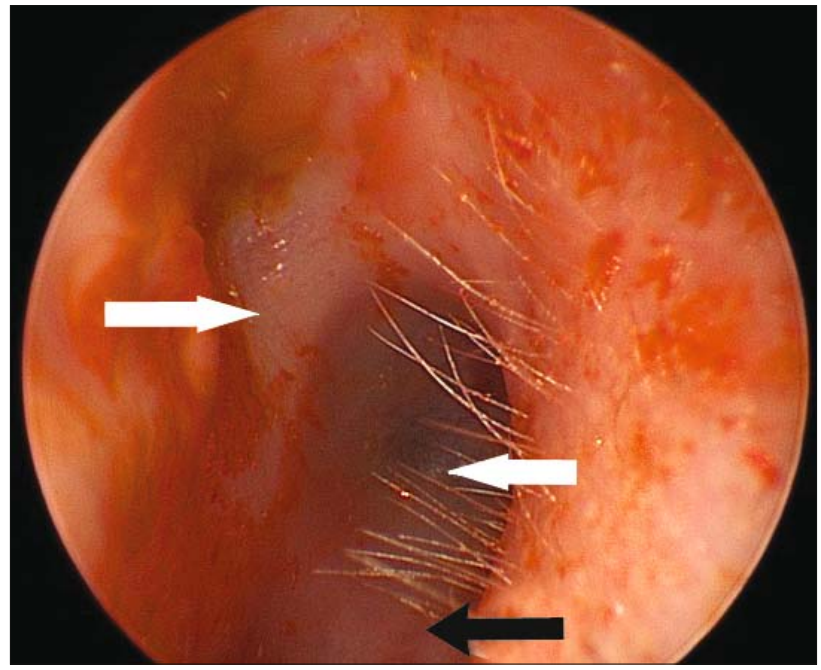

Fig. 1. The postoperative otomicroscopical view after CWD mastoidectomy, right side. Complete closure of the trepanation cavity by soft tissue overlain by epithelium (white arrows). Anterior tympanomeatal angle blunting (black arrow).

were blinded to the surgeon, as much of the revision surgery after CWD with the clinical finding of discharing cavity and granulation tissue. Indication for a revision surgery after CWD in patients with a complete cavity closure were made on positive DWI MR finding.

The presence, macroscopic character and precise localization of all pathological lesions such as fibrosis, chronic inflammatory tissue and cholesteatoma were noted. The clinical diagnosis of cholesteatoma in all cases was confirmed by histological examination and correlated with the findings on MR.

\section{Statistical analysis}

The sensitivity, specificity, positive predictive value and negative predictive value of non-echo planar DWI MR for this disease were calculated (Fig. 1).

\section{Results}

In the whole sample of 27 operated ears, cholesteatoma was histologically diagnosed in $18(67 \%)$ cases, which included 8 (45\%), $9(50 \%)$ and $1(5 \%)$ case, represented as recidive after CWD, residual and recurrent after CWU form, respectively. In the other 8 cases, inflammatory granulation tissue or fibrosis was confirmed. In one patient, no pathological mass was found during the second-look operation.

Of the 18 proven cholesteatomas, 15 were correctly diagnosed on preoperative DWI MR. Three false negative cases were residual cholesteatomas after CWU surgery $2.5 \mathrm{~mm}, 2 \mathrm{~mm}$ and $1 \mathrm{~mm}$ in size. One false positive DWI MR scan in a revision surgery after CWD was caused by an artefact on air-bone interface. The detected cholesteatomas had an average size of $9 \mathrm{~mm}$, the smallest diameter was $3 \mathrm{~mm}$ and the largest was $23 \mathrm{~mm}$ (Fig. 2).
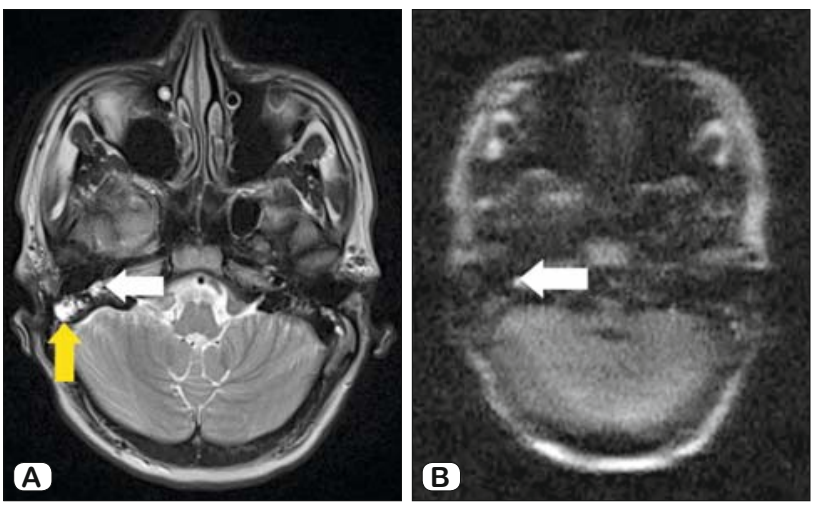

Fig. 2. MR of the right temporal bone, axial images: cholesteatoma and inflammatory tissue in the right middle ear. A, T2-weighted image showing homogenous high signal intensity in the perisinus mastoid cells (black arrow) and in the mesotympanum and posterior hypotympanum (white arrow). B, DWI showing a homogenous high signal intensity only in meso/hypotympanal lesion (white arrow) leading to a diagnosis of $4 \mathrm{~mm}$ residual cholesteatoma.
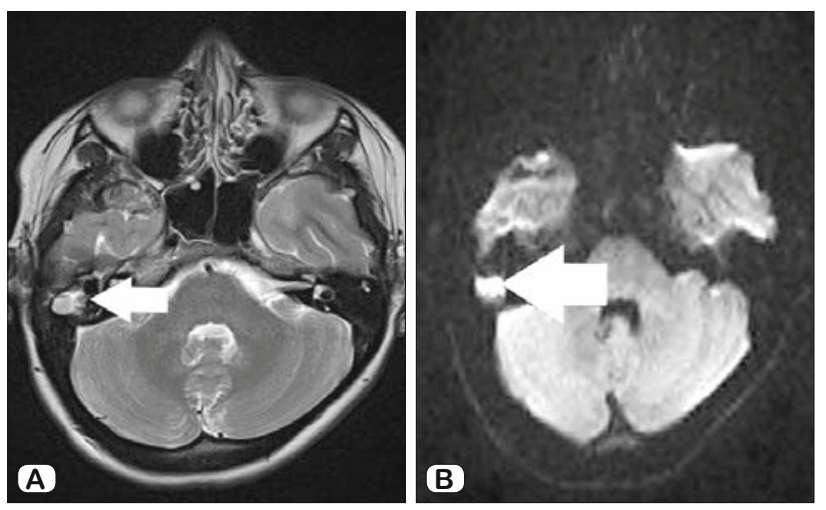

Fig. 3. MR of the right temporal bone, axial images: cholesteatoma in the right, spontaneously closed trepanation cavity after CWD mastoidectomy. A, T2-weighted image showing a homogenous high signal intensity in the majority of trepanation cavity (white arrow). B, DWI showing a homogenous high signal intensity in the lesion (white arrow) leading to a diagnosis of large $13 \times 9 \mathrm{~mm}$ residual cholesteatoma.

In the group of patients, $15 / 27$ (55\%) were true positive, $8 / 27$ (30\%) true negative, $1 / 27$ (4\%) false positive and 3/27 (11\%) false negatives (Tab. 1).

In the subgroup of 15 patients after CWD, 8/9 (88.8\%) preoperatively detected cholesteatomas by DWI MR were peroperatively confirmed (Fig. 3). All lesions were localized in the trepa-

Tab. 1. Clinical and radiological correlation of cholesteatoma findings.

\begin{tabular}{lccc}
\hline & $\begin{array}{c}\text { Cholesteatoma } \\
\text { present }\end{array}$ & $\begin{array}{c}\text { Cholesteatoma } \\
\text { absent }\end{array}$ & Total \\
\hline $\begin{array}{l}\uparrow \text { signal intensity } \\
\text { on DWI MR }\end{array}$ & $15^{*}$ & 1 & 16 \\
\hline $\begin{array}{l}\downarrow / 0 \text { signal intensity } \\
\text { on DWI MR }\end{array}$ & $3 * *$ & 8 & 11 \\
\hline Total & 18 & 9 & 27 \\
\hline$* 8 / 15$ recidive after CWD, $6 / 15$ residual and $1 / 15$ recurrent cholesteatoma after \\
CWU, ** residual cholesteatomas after CWU $\leq 2.5$ mm in size
\end{tabular}




\section{5-520}

nation cavity. In the other 6 cases, cholesteatoma was correctly excluded by the imaging method. In one patient, DWI MR showed an increased signal intensity in small lesion $4 \mathrm{~mm}$ in size, but peroperatively only granulation tissue was found. The diameter of the detected cholesteatomas ranged from 9 to 23 (mean 12) $\mathrm{mm}$.

DWI presented sensitivity, specificity, positive and negative predictive value of $100 \%, 85.7 \%, 88.8 \%$ and $100 \%$ respectively in the subgroup of patients after CWD mastoidectomy.

The overall sensitivity, specificity, positive and negative predictive value of non-EPIDWI for this disease were $83.3 \%, 88.8 \%, 93.8$ $\%$ and $72.7 \%$ respectively. The accuracy of the method was $85.2 \%$.

\section{Discussion}

After the primary cholesteatoma surgery, there is a risk of nonradically removing of the lesion (residual cholesteatoma) or a development of new cholesteatoma based on new retraction pocket containing keratin (recurrent cholesteatoma) (21).

This concerns especially CWU due to a higher rate of recidivous cholesteatoma usually present in the areas hidden from clinical examination. In past, all patients after this technique had to undergo routine second-look surgery several months after their primary cholesteatoma surgery to rule out residual and/or recurrent disease (22).

To avoid potential operational risks in negative cases, noninvasive imaging methods in detection of recidive lesion have been investigated.

HRCT in the detection of recidivous cholesteatoma has $43 \%$ sensitivity and $50 \%$ specificity (23), significantly lower than for primary cholesteatomas $(15,24)$.

Echo planar (EPI) sequence DWI MR provided new and better quality. Its disadvantages are artefacts and the inability to show lesions less than $5 \mathrm{~mm}$ in size $(15,25,26)$. For these reasons, some authors combined this method with T1-weighted images after intravenous administration of gadolinium contrast agent (25). Differential diagnostic criterion, distinguishing cholesteatoma from other tissues, is the absence of signal enhancement in the former. However, this method was time consuming, and did not find wider application in clinical practice.

The use of non-EPI DWI, due to a reduced slice thickness, higher spatial resolution and reduced susceptible artefacts in temporal bone allowing visualization of smaller size lesions, has been shown to be promising alternative for invasive second-look surgery in screening for recidivous cholesteatoma. It has a very high sensitivity and specificity, high positive and negative predictive values, and is also proposed to be suitable for detection of primary cholesteatomas in disputable cases, both in children and in adult patients $(27,28)$.

In our study, we found $83.3 \%$ overall sensitivity. Similar values ranging from 82-96\% are reported in other publications (29, $30,31,32,33,34,35,36)$. Some authors even indicate absolute numbers $(16,37,38,39,40)$. In contrast, lower, $76 \%(41)$ and 62 $\%$ (42) sensitivities are also described. The reason may have been a relatively large number of false negatives in the first named (41) and small number of patients in the second (42).
We achieved a specificity of $88.8 \%$, which corresponds to the majority of published studies with values ranging from $87.5 \%$ to $93 \%(16,29,31,34,35,41,42)$. Other authors reported $100 \%$ values $(30,37,38,39,40,42)$. Exceptionally, Profant et al (36) and Garrido et al (32) reported lower values, of $71 \%$ and $55 \%$, which were caused by a relatively high incidence of false positives and small number of examinations, respectively.

In our group, there were four false-negative findings. Three of them were residual cholesteatomas $\leq 2.5 \mathrm{~mm}$ in size. Various authors indicate different critical sizes for detection on DWI MR. Some believe it is $2 \mathrm{~mm}$, regardless of device used $(29,34,39)$, while others refer to $3 \mathrm{~mm}(30,31,33,36,37,38,40)$, or $4 \mathrm{~mm}$ $(41,42)$, or even $5 \mathrm{~mm}(16)$.

The sensitivity of the method to small cholesteatomas is lower than that for cholesteatomas of larger dimensions (41). The reasons why these small lesions are not viewable on DWI MR are related to the spatial resolution of DWI MR.

The source of the signal on DWI MR is restriction of diffusion in keratin. For this reason, a positive result is found even in case of filled retraction pocket (30). In contrast, those with small formations $(29,34,41)$ or any keratin-containing materials $(31,41)$ are not detectable by DWI MR. The same is true of mural cholesteatoma, where spontaneous evacuation of content is carried out $(35,42)$.

In our previous study (43), we demonstrated in the group of false negatives primary $4 \mathrm{~mm}$ cholesteatoma associated with cholesterol granuloma. The same case is described by Akkari et al (29), who in the group of non-operated and previously operated ears didn't detect cholesteatoma in 1 of 2 patients. Cholesterol granuloma typically shows a high signal intensity on T1- and T2-weighted images and does not show a diffusion restriction on DWI. Explanation of false negative is that cholesterol granuloma overlaps the signal of the cholesteatoma. The same mechanism obviously also applies to the signal for cholesteatomas associated with hematoma (36). Another possible cause of false negative results are motion artefacts (33).

A false positive finding in this study was observed in one patient, in whom in a second-look operation only granulation tissue and scar in the mastoid process was confirmed. It was caused by an artefact arising from air-bone interface. According to Plouin-Gaudon et al (42) artefacts from dental braces may be the reason of above as well. A positive DWI MR finding can imitate bone powder (32), used e.g. to cover the lateral semicircular canal fistula (16), bone apositum in the typanic cavity (35), transplanted fat used to obliteration of mastoidectomy cavity (44), granulation tissue (41), or foreign material based on polymeric silicone compounds (Silastic) (25). False positive findings are also described in the cases of empyema (44), abscess $(32,36)$ and purulent content in the mastoid (29), in which the increased signal intensity on non-EPIDWI is primary caused by restricted diffusion and results less from $\mathrm{T} 2$, shine-through" effect.

In addition to the aforementioned factors, the results of examination are effected by technical parameters of devises. Elefante et al (45) demonstrated a higher sensitivity in multishot than in single shot echo planar (EPI) sequence using 1.5T MR devices. The values depending on the evaluating radiologist, ranged from $96 \%$ to $100 \%$, and $79 \%$ to $96 \%$, respectively. In contrast, the 
specificity of both modalities were comparable (75\% vs $87 \%$ ). The Elefante (45) results are consistent with Yamashita (46), who showed a significantly higher sensitivity in 3D turbo field-echo with diffusion-sensitized driven-equilibrium preparation (TFE-DSDE) than single-shot echo-planar imaging using 3.0T MR devices ( $36.7 \%$ vs $83.3 \%$ ). Low value sensitivity in single shot is caused by susceptibility artefacts associated with false-negative findings.

The Lincot (47) study compared the sensitivity and specificity of the single shot non-echo planar (non-EPI) sequence for $1.5 \mathrm{~T}$ and 3.0T units. In the first case, the sensitivity was $92.9 \%$ and 97.6 $\%$ in the second. Corresponding values of specificity were lower, $92.1 \%$ and $78.9 \%$, respectively. The author explained the higher number of false positives, especially in 3.0T MR, associated with granulation tissue. Potential increase in specificity using additional sequences is questionable due to ambiguous results and relative small number of subjects used in this study.

In contradiction to CWU mastoidectomy, revision surgery after CWD propter recidivous cholesteatoma is mainly indicated by positive otomicroscopical finding.

Spontaneous partial or complete closure of the trepanation cavity after CWD is a rare condition, making the otomicroscopical examination in the detection of recidivous cholesteatoma problematic or impossible. It's debatable, whereas indicate these cases to revision surgery, especially if patients are asymptomatic. But there is a risk of severe complication if potential cholesteatoma will be left undetected (48).

In the subgroup of patients after CWD mastoidectomy, we found $88.8 \%$ positive predictive value and $100 \%$ negative predictive value of non-EPI DWI MR in the detecting of recidivous cholesteatoma. An interesting finding was that 3/8 (37\%) true positive patients were long-term symptomless.

To the best of our knowledge, there are no published studies that investigated the detection of recidivous cholesteatoma after CWD by the imaging method. There has been only one similar case report in the literature published by McJunkin and Chole (49).

Recent data in literature tend to prove that DWI MR allows more reliable detection of recidive cholesteatoma after CWU procedure, thus selection of patients requiring second-look surgery, and our results are in agreement with literature.

Furthermore, based on this preliminary experience, we propose to add non-EPI DWI MR as a screening method also in cases after CWD with a complete closure of the trepanation cavity by soft tissue to rule out cholesteatoma. By doing so, severe complications caused by the disease can be prevented.

\section{References}

1. Chrobok V, Pellant A, Profant M: Cholesteatom spánkové kosti. Havlíčkův Brod: Tobiáš, 2008: 70-79.

2. Olsen JM, Ribeiro FdeA, Yasui MM, Dos Santos IT. Hearing loss assessment in primary and secondary acquired cholesteatoma. Braz J Otorhinolaryngo 12015; 81 (6): 653-657.

3. Kuo CL, Shiao AS, Yung M, Sakagami M, Sudhoff H, Wang CH, Hsu CH et al. Updates and knowledge gaps in cholesteatoma research. Biomed Res Int 2015; 854024.
4. Ng JH, Zhang EZ, Soon SR, Tan VY, Tan TY, Mok PK, Yuen HW. Pre-operative high resolution computed tomography scans for cholesteatoma: has anything changed? Am J Otolaryngol 2014; 35 (4): 508-513.

5. Kuo CL, Liao WH, Shiao AS. A review of current progress in acquired cholesteatoma management. Eur Arch Otorhinolaryngol 2015; 272 (12): 3601-3609.

6. Minovi A, Venjacob J, Volkenstein S, Dornhoffer J, Dazert S. Functional results after cholesteatoma surgery in an adult population using the retrograde mastoidectomy technique. Eur Arch Otorhinolaryngol 2014; 271 (3): 495-501.

7. Kerckhoffs KG, Kommer MB, van Strien TH, Visscher SJ, Bruijnzeel H, Smit AL, Grolman W. The disease recurrence rate after the canal wall up (CWU) or canal wall down (CWD) technique in adults. Laryngoscope 2015 Sep 25.

8. Lailach S, Kemper M, Lasurashvili N, Beleites T, Zahnert T, Neudert M. Health-related quality of life measurement after cholesteatoma surgery: comparison of three different surgical techniques. Eur Arch Otorhinolaryngol 2015; 272 (11): 3177-3185.

9. Cho SW, Cho YB, Cho HH. Mastoid obliteration with silicone blocks after canal wall down mastoidectomy. Clin Exp Otorhinolaryngol 2012; 5 (1): $23-27$.

10. Liu SC, Wang CH, Huang BR. Obliteration of Radical Cavities and Total Reconstruction Procedure Without Staging After Canal Wall Down Mastoidectomy: Long-term Results. Clin Exp Otorhinolaryngol 2015; 8 (3): 230-236.

11. Koval J. Chirurgická liečba chronického stredoušného zápalu. Bratislava: USPO, 1998, 81-90.

12. Osborn AJ, Papsin BC, James AL. Clinical indications for canal wall-down mastoidectomy in a pediatric population. Otolaryngol Head Neck Surg 2012; 147 (2): 316-322.

13. Tomlin J, Chang D, McCutcheon B, Harris J. Surgical technique and recurrence in cholesteatoma: a meta-analysis. Audiol Neurootol 2013; 18 (3): $135-142$.

14. Hulka GF, McElveen JT Jr. A randomized, blinded study of canal wall up versus canal wall down mastoidectomy determining the differences in viewing middle ear anatomy and pathology. Am J Otol 1998; 19 (5): 574-578.

15. Ganaha A, Outa S, Kyuuna A et al. Efficacy of diffusion-weighted magnetic resonance imaging in the diagnosis of middle ear cholesteatoma. Auris Nasus Larynx 2011; 38 (3): 329-334.

16. Dubrulle F, Souillard R, Chechin D, Vaneecloo FM, Desaulty A, Vincent C. Diffusion-weighted MR imaging sequence in the detection of postoperative recurrent cholesteatoma. Radiology 2006; 238 (2): 604-610.

17. Li PM, Linos E, Gurgel RK, Fischbein NJ, Blevins NH. Evaluating the utility of non-echo-planar diffusion-weighted imaging in the preoperative evaluation of cholesteatoma: a meta-analysis.Laryngoscope 2013; 123 (5): $1247-1250$.

18. Hagmann P, Jonasson L, Maeder P, Thiran JP, Wedeen VJ, Meuli R. Understanding diffusion MR imagingtechniques: from scalar diffusionweighted imaging to diffusion tensorimaging and beyond. Radiographics 2006; 26 (Suppl 1): 205 - 223.

19. Gaillardin L. Lescanne E, Morinière S, Cottier JP, Robier A. Residual cholesteatoma: prevalence and location. Follow-up strategy in adults. Eur Ann Otorhinolaryngol Head Neck 2012; 129 (3): 136-140. 
20. Roger G, Denoyelle F, Chauvin P, Schlegel-Stuhl N, Garabedian EN. Predictive risk factors of residual cholesteatoma in children: a study of 256 cases. Am J Otol 1997; 18 (5): 550-558.

21. Neudert M, Lailach S, Lasurashvili N, Kemper M, Beleites T, Zahnert T. Cholesteatoma recidivism: comparison of three different surgical techniques. Otol Neurotol 2014; 35 (10): 1801-1808.

22. Wilson KF, Hoggan RN, Shelton C. Tympanoplasty with intact canal wall mastoidectomy for cholesteatoma: long-term surgical outcomes. Otolaryngol Head Neck Surg 2013; 149 (2): 292-295.

23. Blaney SP, Tierney P, Oyarazabal M, Bowdler DA. CT scanning in "second look" combined approach tympanoplasty. Rev Laryngol Otol Rhinol (Bord) 2000; 121 (2): 79-81.

24. Chee NW, Tan TY. The value of pre-operative high resolution CT scans in cholesteatoma surgery. Singapore Med J 2001; 42 (4): 155-159.

25. Venail F, Bonafe A, Poirrier V, Mondain M, Uziel A. Comparison of echo-planar diffusion-weighted imaging and delayed postcontrast T1weighted MR imaging for the detection of residual cholesteatoma. AJNR Am J Neuroradiol 2008; 29 (7): 1363-1368.

26. Vercruysse JP, De Foer B, Pouillon M, Somers T, Casselman J, Offeciers $\mathbf{E}$. The value of diffusion-weighted MR imaging in the diagnosis of primary acquired and residual cholesteatoma: a surgical verified study of 100 patients. Eur Radiol 2006; 16 (7): 1461-1467.

27. van Egmond SL, Stegeman I, Grolman W, Aarts MC. A Systematic Review of Non-Echo Planar Diffusion-Weighted Magnetic Resonance Imaging for Detection of Primary and Postoperative Cholesteatoma. Otolaryngol Head Neck Surg 2016; 154 (2): 233-240.

28. Nash R, Wong PY, Kalan A, Lingam RK, Singh A. Comparing diffusion weighted MRI in the detection of post-operative middle ear cholesteatoma in children and adults. Int J Pediatr Otorhinolaryngol 2015; 79 (12): 2281-2285.

29. Akkari M, Gabrillargues J, Saroul N, Pereira B, Russier M, Mom T, Gilain L. Contribution of magnetic resonance imaging to the diagnosis of middle ear cholesteatoma: analysis of a series of 97 cases. Eur Ann Otorhinolaryngol Head Neck Dis 2014; 131 (3): 153-158.

30. Alvo A, Garrido C, Salas Á, Miranda G, Stott CE, Delano PH. Use of non-echo-planar diffusion-weighted MR imaging for the detection of cholesteatomas in high-risk tympanic retraction pockets. AJNR Am J Neuroradiol 2014; 35 (9): 1820-1824.

31. De Foer B, Vercruysse JP, Bernaerts A et al. Middle ear cholesteatoma: non-echo-planar diffusion-weighted MR imaging versus delayed gadolinium-enhanced T1-weighted MR imaging-value in detection. Radiology 2010; 255: 866-872.

32. Garrido L, Cenjor C, Montoya J, Alonso A, Granell J, GutiérrezFonseca R. Diagnostic capacity of non-echo planar diffusion-weighted MRI in the detection of primary and recurrent cholesteatoma. Acta Otorrinolaringol Esp 2015; 66 (4): 199-204.

33. Huins CT, Singh A, Lingam RK, Kalan A. Detecting cholesteatoma with non-echo planar (HASTE) diffusion-weighted magnetic resonance imaging. Otolaryngol Head Neck Surg 2010; 143 (1): 141-146.

34. Khemani S, Lingam RK, Kalan A, Singh A. The value of non-echo planar HASTE diffusion-weighted MR imaging in the detection, localisation and prediction of extent of postoperative cholesteatoma. Clin Otolaryngol 2011; 36 (4): 306-312

35. Mateos-Fernández M, Mas-Estellés F, de Paula-Vernetta $C$, Guzmán-Calvete A, Villanueva-Martí R, Morera-Pérez C. The role of diffusion-weighted magnetic resonance imaging in cholesteatoma diag- nosis and follow-up. Study with the diffusion PROPELLER technique. Acta Otorrinolaringol Esp 2012; 63 (6): 436-442.

36. Profant M, Sláviková K, Kabátová Z, Slezák P, Waczulíková I. Predictive validity of MRI in detecting and following cholesteatoma. Eur Arch Otorhinolaryngol 2012; 269 (3): 757-765.

37. Dhepnorrarat RC, Wood B, Rajan GP. Postoperative non-echo-planar diffusion-weighted magnetic resonance imaging changes after cholesteatoma surgery: implications for cholesteatoma screening. Otol Neurotol 2009; 30 (1): 54-58.

38. Lehmann P, Saliou G, Brochart C, Page C, Deschepper B, Vallée JN, Deramond H. 3T MR imaging of postoperative recurrent middle ear cholesteatomas: value of periodically rotated overlapping parallel lines with enhanced reconstruction diffusion-weighted MR imaging. AJNR Am J Neuroradiol 2009; 30 (2): 423-427.

39. Pizzini FB, Barbieri F, Beltramello A, Alessandrini F, Fiorino F. HASTE diffusion-weighted 3-Tesla magnetic resonance imaging in the diagnosis of primary and relapsing cholesteatoma. Otol Neurotol 2010; 31 (4): 596-602.

40. Rajan GP, Ambett R, Wun L, Dhepnorrarat RC, Kuthubutheen J, Chow Z, Wood B. Preliminary outcomes of cholesteatoma screening in children using non-echo-planar diffusion-weighted magnetic resonance imaging. Int J Pediatr Otorhinolaryngol 2010; 74 (3): 297-301.

41. von Kalle T, Amrhein P, Koitschev A. Non-echoplanar diffusionweighted MRI in children and adolescents with cholesteatoma: reliability and pitfalls in comparison to middle ear surgery. Pediatr Radiol 2015; 45 (7): 1031-1038.

42. Plouin-Gaudon I, Bossard D, Fuchsmann C, Ayari-Khalfallah S, Froehlich P. Diffusion-weighted MR imaging for evaluation of pediatric recurrent cholesteatomas. Int J Pediatr Otorhinolaryngol 2010; 74 (1): $22-26$.

43. Bakaj-Zbrožková L., Bakaj T., Čecháková E., Heřman M., Stárek I. MR diagnosis of middle ear cholesteatoma using non-echo planar diffusionweighted oimaging (Non-EPI DWI). Ces Radiol 2015; 69 (3): 213-219.

44. Dremmen MH, Hofman PA, Hof JR, Stokroos RJ, Postma AA. The diagnostic accuracy of non-echo-planar diffusion-weighted imaging in the detection of residual and/or recurrent cholesteatoma of the temporal bone. AJNR Am J Neuroradiol 2012; 33 (3): 439-444.

45. Elefante A, Cavaliere M, Russo C et al. Diffusion weighted MR imaging of primary and recurrent middle ear cholesteatoma: an assessment by readers with different expertise. Biomed Res Int 2015; 2015: 597896.

46. Yamashita K, Yoshiura T, Hiwatashi A et al. High-resolution threedimensional diffusion-weighted imaging of middle ear cholesteatoma at 3.0 T MRI: usefulness of 3D turbo field-echo with diffusion-sensitized drivenequilibrium preparation (TFE-DSDE) compared to single-shot echo-planar imaging. Eur J Radiol 2013; 82 (9): 471-475.

47. Lincot J, Veillon F, Riehm $\mathbf{S}$ et al. Middle ear cholesteatoma: Compared diagnostic performances of two incremental MRI protocols including non-echo planar diffusion-weighted imaging acquired on $3 \mathrm{~T}$ and $1.5 \mathrm{~T}$ scanners. J Neuroradiol 2015; 42 (4): 193-201.

48. Khudzhadze MO, Vashakidze NN, Gogniashvili GO, Khelashvili BS. Case report of the middle ear cholesteatoma recidive after canal wall down operation, 2 years later. Georgian Med News 2009; (172173): 25-28.

49. McJunkin J, Chole R. Clinical Utility of MRI for Cholesteatoma Recurrence. Curr Surg Rep 2014; 2: 63.

Received February 24, 2016. Accepted April 9, 2016. 